\title{
An Innovative Training Model for an Organization Embracing Technology
}

\section{Karen Neville University College Cork, Ireland}

Kneville@afis.ucc.ie

\author{
Brian Fitzgerald \\ University of Limerick, Ireland
}

bf@ul.ie

\section{Executive Summary}

The significance of information technology (IT) for modern business and, indeed, research in general cannot be questioned, as its sheer pervasiveness adequately attests. However, simplistic views of technological utopianism are now being offset by accounts of technological dystopianism. Clearly organizational management have wholeheartedly subscribed to an IT future as a staggering 41 percent of total capital expenditure in US organizations currently goes on IT. However, organizations face enormous difficulty in trying to achieve successful training programmes in the instruction and use of IT. This research study involved the construction and implementation of an IT training programme to inform midcareer employees, in a large multinational organization, of the benefits of IT. Davis (1989) identified two constructs as relevant to user acceptance of technology, namely ease of use (EOU) and perceived usefulness $(P U)$. These constructs were operationalised into a set of principles to underpin the training programme which was delivered in two phases, each specifically addressing one of Davis' constructs. While the research is at an early stage, some preliminary lessons have been learned. For example, Davis' chain of causality operates in a fairly simple linear fashion, in that ease of use (EOU) is identified as a necessary pre-condition before perceived usefulness (PU) can be achieved. However, our research would suggest that this relationship is more interrelated and complex. Early signs suggest that the relationship between ease of use and perceived usefulness is not a simple linear sequential one whereby EOU must first be established as a necessary precondition for PU which in turn successfully leads to user acceptance of technology. Rather, the perceived usefulness of the technology can serve as a significant motivator initially which will help overcome EOU issues. Thus rather than operating in a sequential chain, the EOU and PU constructs may operate in a parallel cyclical fashion.

Keywords: Information Technology, IT Training Constructs, Web-based Training

\section{Introduction}

Organizations face enormous difficulty in trying to achieve successful training programmes in the use of IT. Davis (1989) identified two constructs as relevant to user acceptance of technology, namely ease of

Material published as part of this journal, either on-line or in print, is copyrighted by the publisher of the Journal of Information Technology Education. Permission to make digital or paper copy of part or all of these works for personal or classroom use is granted without fee provided that the copies are not made or distributed for profit or commercial advantage AND that copies 1) bear this notice in full and 2) give the full citation on the first page. It is permissible to abstract these works so long as credit is given. To copy in all other cases or to republish or to post on a server or to redistribute to lists requires specific permission and payment of a fee. Contact Editor@JITE.org to request redistribution permission. use (EOU) and perceived usefulness (PU). These constructs were operationalised into a set of principles to underpin the training programme which was delivered in two phases, each specifically addressing one of Davis' constructs. While Davis' constructs have been rigorously validated empirically in a number of quantitatively-oriented studies, very little research of a qualitative nature has been conducted on his constructs. Thus, the research approach adopted for the study was a quali- 


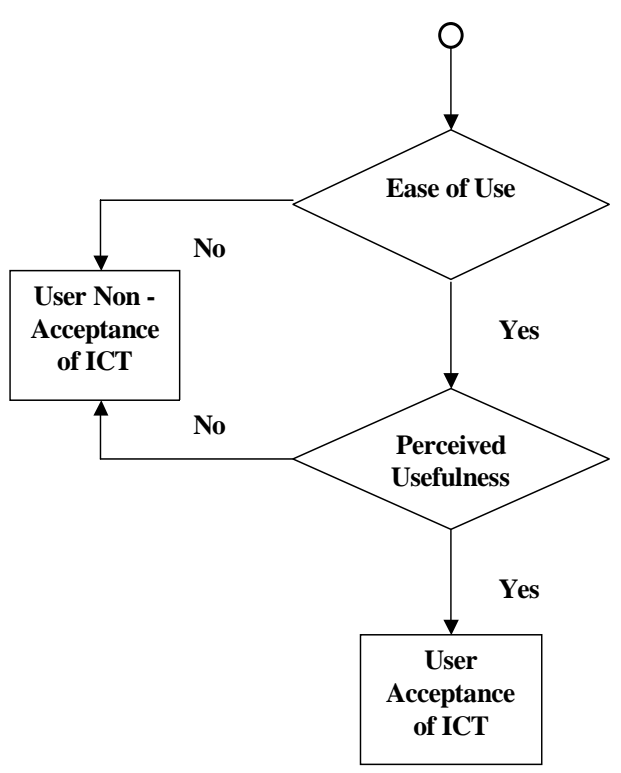

Figure 1: Davis' Conceptualization of User Acceptance Constructs tative, reflexive one. Davis' constructs informed the construction of both the training programme and framework initially. The evaluation of the success of the programme will be determined through surveys and indepth interviews with the participants and it is intended that the final framework will add some 'thick description' and further elaborate the original constructs.

\section{Research Objective}

Given the importance of information technology (IT) for modern business, it is vital that organizations can achieve successful training in the IT area. However, this is an area which has proved problematic in general (Neumann, 1995), and, very particularly, in the case study organization involved in this research who had implemented a number of IT training programmes in the past, all of which had failed to

increase the use of IT in the organization. Thus, the objective of this research was to construct and implement a training programme which would increase the subsequent usage of IT in the daily work practices of those who undertook the training.

From a research point of view, the additional goal was to investigate in depth the factors that can lead to successful training in IT. Additionally applying Davis' EOU/PU constructs to a "live" training setting provided the researchers with the potential to deepen the understanding of these constructs and their interrelationships. Furthermore a subsequent goal of the research is to exploit the model as a tool to inform investigations into other cases.

\section{Theoretical Foundations}

Davis (1989) represents one of the original and most influential researchers in the area of user acceptance of IT. He synthesises the findings of a range of diverse research streams to propose a number of constructs that are relevant to technology acceptance. These constructs fall into two broad categories, ease of use (EOU) and perceived usefulness (PU). Davis suggests a chain of causality between these categories: greater ease of use leads to higher perceived usefulness which in turn leads to more usage of technology (see Figure. 1). These constructs have been validated in rigorous tests in empirical studies in a variety of settings (Adams et al., 1992; Davis, 1989; Davis et al., 1989; Henderson et al., 1998). However, the constructs have generally been researched in a very quantitatively-oriented fashion. The objective of this research was therefore to operationalise these constructs in an actual training programme and consider them in depth following a more qualitative research approach. Further details on the operationalisation of Davis' constructs in the training programme are provided in a following section.

\section{Research Approach}

The research context was that of a single case study organization and involved the construction and implementation of an IT training programme for mid-career employees. The initiative was entitled MEET 
(Mid-career Employees Embracing Technology). The overall research orientation was qualitative and reflexive in nature. A grounded theory perspective was adopted, and in line with this, an initial framework incorporating Davis' constructs as preliminary 'seed categories' was created (see Figure. 2). The intention is to further validate these constructs and to elaborate the framework as the research progresses.

\section{The MEET Training Programme at Golden Vale Plc: Current Status}

\section{Background to the Case}

Since 1947, Golden Vale plc has been one of Ireland's largest food co-operatives, with an annual turnover of over Ir£15m. The company is a vibrant force not only in the Irish dairy industry, but it is also one of the top cheese processors in Europe, employing 2,100 people in Ireland and over 300 in its foreign subsidiaries. Golden Vale Plc. is based in the eponymous 'golden vale', a region noted for the quality of the agricultural land and its produce. The company are sited in one of the largest towns in the region, with a population of 2,667. Golden Vale is by far and away the largest employer in the area. The majority of their employees are local residents, and while the younger employees would have a high standard of education, many of the mid-career employees (aged 35 and over) would have joined Golden Vale in their teens, without even finishing their second-level education in many instances. These employees learned on the job, and have no base of educational or technical skills to equip them to work in other industry sectors. Thus, any slump in the long-term viability of Golden Vale would clearly have a catastrophic social and economic effect on the region. Given this, the Irish government, obviously mindful of a number of disastrous social catastrophes in other Irish towns, which had been dependent on a single large employer who failed to survive, funded a training initiative which was intended to provide a solid training in IT for mid-career employees and provide a model for other groups (both organizational and academic) to follow. Thus, one of the primary objectives of the initiative was to provide a more skilled work group who would be able to find work more readily in other industry sectors should Golden Vale experience a catastrophe. Employees are also aware of the risk if something should occur, however they are also aware of the importance of IT literacy in improving their career prospects within Golden Vale.

The company had initiated several IT training programmes in the past, facilitated by their internal IT department who brought in training consultants to provide off-the-shelf training courses in standard IT packages, such as word processing and spreadsheets. These training programmes, while having been applied in a textbook fashion, were acknowledged as having had little or no lasting effect in persuading employees to make ongoing use of technology in their work. The company decided to adopt a different approach for this initiative, and contacted the main university in the region (where the authors of this paper work) to seek assistance. The authors met with the IT and HR staff in the company and the name for the project was coined, M.E.E.T (Mid-career Employees Embracing Technology). The approach taken in previous training programmes in the company was discussed, and some of the participants were interviewed. It quickly became apparent that the employee base was not homogeneous in relation to IT literacy; thus, standard training programmes which were aimed at a 'common denominator' level be inappropriate, in that those who were more advanced would find the material boring and lose interest, while those who didn't understand the rudiments would be unable to engage with the material in the first place.

\section{Constructing the MEET Training Programme}

The authors decided to follow the model implied by Davis, discussed above, in that significant attention was devoted to ensuring that the programme would address the ease of use and perceived usefulness 
categories. The preliminary stage was to conduct a training needs analysis, using a consultancy company who were expert in this area. This analysis was carried out over a two-month period by 12 experts from the consultancy company and involved highly-participative workshops and in-depth interviews with a representative sample of 38 potential participants in the training programme. The outcome of this analysis suggested that the participants could be categorised into four levels of technical capability ranging from basic (level 1) to advanced (level 4). However, only two participants were identified as advanced90 percent of the sample was in the first two levels, with equivalent numbers in each. Given this outcome, the target group of mid-career employees was divided into three groups for training, basic, intermediate and advanced (levels 3 and 4 were combined to create the latter group).

We decided to address each of Davis' two categories by adopting a two-phased training approach (see Figure 2). The first phase proposed was a generic training phase, during which the basic IT concepts would be covered at a pace appropriate to each group, thus addressing the ease of use construct. Following completion of this generic training, the second phase would involve applied training customised to address the everyday work tasks faced by the participants, thus addressing the perceived usefulness construct. The chronological ordering of these phases is congruent with Davis' (1989) proposed chain of causality, mentioned above, namely that greater ease of use would facilitate a higher perceived usefulness of IT, thereby leading to greater usage.

Space precludes a complete discussion of these programmes, but the discussion below indicates how the various facets of the training programme were chosen to satisfy one or other of Davis' constructs.

\section{MEET Programme Constructs Addressing Ease of Use (EOU) Constructs}

The items identified by Davis (1989) as being significantly correlated with ease of use include easy-tolearn, controllable, clear and understandable, and (not surprisingly!) easy to use. As already mentioned, most previous studies have sought to validate these in rigorous quantitative experiments. In this study,

\begin{tabular}{|l|l|l|}
\hline \multicolumn{1}{|c|}{ COMPONENTS } \\
\hline $\begin{array}{l}\text {-Literacy: to ensure a threshold } \\
\text { level of literacy achieved. } \\
\text { •Categorization: based on } \\
\text { participant's current level of } \\
\text { literacy. } \\
\text { •Resources: State of the art } \\
\text { equipment. } \\
\text {-Duration: restricted to two } \\
\text { hours to avoid repetition and } \\
\text { complexity. } \\
\text { •Class size: maximum of } 6 \\
\text { participants to ensure quality. } \\
\text {-Instructors: a trainee-instructor } \\
\text { ratio of 3:1, to provide personal } \\
\text { attention if required. } \\
\text {-User documentation: } \\
\text { customized manuals that are both } \\
\text { user friendly and job related. } \\
\text { Support system: in the form of a } \\
\text { W B B system to enable feedback } \\
\text { and queries. }\end{array}$
\end{tabular}

\section{Figure 2: Framework for Operationalising the M.E.E.T Programme}

*The WBT System was developed to support both phases of the training programme. It enabled the employees to participate in the customisation (EOU) of the system and to add to the system through the discussion forum (PU). The arrows used in the diagram highlight the complexity of the inter-relationship between the two constructs (EOU/PU), suggesting that not only does EOU lead to PU but that PU increases the level of EOU (See Conclusions below.). 
we were concerned with operationalising these in practice in a real situation, and thus a more qualitative approach was deemed appropriate. The following facets of the programme indicate how this 'ease of use' construct was operationalised:

- From the outset, the initial generic training phase was intended to ensure that all participants achieved a reasonable level of literacy in IT.

- Participants were allocated to one of three groups based on their current level of IT capability. This ensured that the common denominator for training in each group was uniform, thus reducing the possibility that participants might be too embarrassed to reveal their lack of understanding of training material.

- All sessions were held in a very well-equipped training laboratory, with state-of-the-art technology for trainers and participants.

- The training laboratory was in a 'neutral' venue, a short distance away from the factory floor where the participants worked every day. This helped participants to focus on the training and avoid distractions.

- The maximum duration of training sessions was restricted to two hours, thus ensuring that participants did not become overwhelmed with complex material, or bored with repetition of material already understood.

- The number of participants at each training session was kept low-a maximum of six participants. This was intended to ensure that all participants' performance and progress could be monitored to ensure they understood the concepts.

- Two instructors were in attendance at each session, thus achieving a trainee-instructor or researcher ratio of 3:1. One generally led the instruction, while the other had a roving role, visiting each workstation to ensure that all participants understood the material. When difficulties were encountered, the instructor would provide one-on-one instruction in a discreet manner until the difficulty was fully resolved.

- All the instructors (including one of the authors of this paper) were selected following personal interviews by the company. The company was in a rural location, and the participants had a rural background. The instructors selected had a rural background in the main. The company were of the opinion that one of the reasons previous training initiatives had failed to deliver was that instructors were perceived as dynamic 'city-types' who were more comfortable with Internet chat sessions over decaffeinated latte in cyber-cafes rather than in discussing hogget ${ }^{1}$ prices in a small tea-room. One can debate the rights and wrongs of such social stereotyping, but the rapport built up between the participants and the instructors was very impressive.

- The training material was designed to be user-friendly. Different booklets were prepared for each element of the training. Exercises were chosen from the daily work routines of participants

- A special Web-based training (WBT) system was also constructed to support the training in phase 1 and 2 . The training material was available on-line, but in addition, a discussion forum was imple-

\footnotetext{
${ }^{1}$ A type of sheep--rather ironic given the name.
} 
mented. This enabled participants to provide feedback (anonymously, if desired) to the instructors. It also allowed them to pose queries, which other participants or the instructors could answer. All participants could see the initial queries and the discussion stream of answers from other participants and the instructors. This further extended the reach of the training as workers could log on to the Web system at home or at their work, during night-shift, for example, and pose questions for which answers would be available when they next logged on. The facility also allowed the employees to voice their satisfaction regarding the different elements of the training. This provided the participants with the opportunity to take part in the ongoing customisation of the training model, and therefore increase the likelihood of user acceptance (Whitten et al., 1994; Fitzgerald, 1996; Bocij et al., 1999).

\section{MEET Programme Constructs Addressing Perceived Usefulness (PU)}

The items identified by Davis (1989) as reflecting the 'perceived usefulness' construct include, working more quickly, increased productivity, improved effectiveness and job performance, making job easier, and again the obvious item, useful. These were operationalised in the study in the following way:

- At a high level, the separation of the initial generic training phase from the subsequent applied training phase ensured that the usefulness of the technology could be demonstrated in the second training phase. Participants had achieved a base level of capability, and the authors had made several visits to them in their work environment, inspecting work documents with a view to seeing how technology could be incorporated into their everyday work routines to solve problems.

- Examples include the creation of templates to automate manual activities like creating time sheets and home accounts. Systems, already in existence, were also demonstrated to highlight the application of technology within the company. These exercises stimulated ideas in the application of the skills developed by the participants from the programme.

- In addition to the examples suggested by the instructors, participants were encouraged to identify ways in which the technology could be employed in their work. Potential projects were explored during the training sessions in the applied training phase.

- The participants were, like the general public world-wide, very interested in the Internet and World Wide Web, but felt their knowledge in the area was very limited. It was decided to leverage this to get participants to buy into the training process. Thus, the first introductory session for all groups of participants was a 'web surfing' session. This served to break the ice between instructors and participants in a friendly atmosphere. Participants were shown the rudimentary details and then began surfing the web themselves using various search engines, and visiting sites recommended by the instructors.

This session was also used to demonstrate the Web system, which had been constructed specially to support the training. As already mentioned, it had been decided as a matter of policy that sessions would not exceed two hours. However, this introductory session stretched this limit most as participants were so enthusiastic and wanted to continue. The enthusiasm of the first wave of participants ensured that all later groups were very keen to get started on the training themselves. The participants were all very satisfied with their knowledge of the web and saw it as a very useful skill to have achieved. 


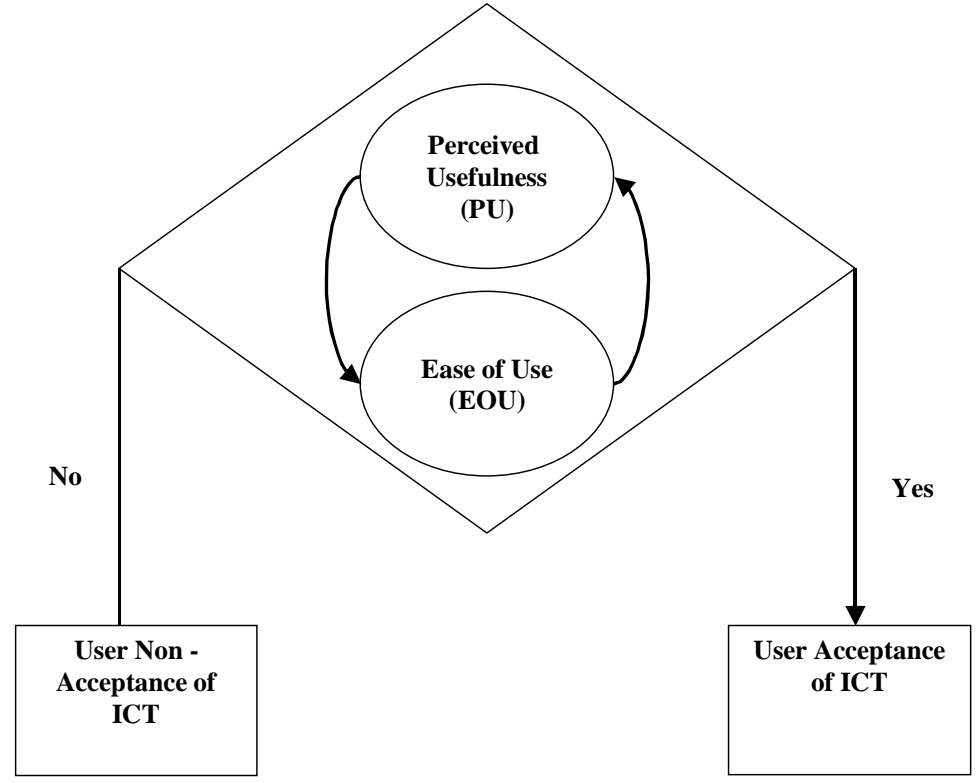

Figure 3: Alternative Concept of User Acceptance
- Upon completion of the generic training phase, participants visited the university for a formal diploma presentation ceremony. The diploma parchments were accepted with pride, and many spoke of their satisfaction with their achievement, for many, the only educational certification they had ever received.

- It was intended that the training would be a dynamic and organic experience, capable of selfperpetuation. Thus, the advanced group was considered to have potential to play a considerable hands-on role in promoting the use of IT throughout the company and in future training initiatives. This would be reflected in the job status of these individuals, thus, it would serve as a significant motivator.

\section{Conclusion}

While the research is at an early stage, some preliminary lessons have been learned. For example, Davis' chain of causality operates in a fairly simple linear fashion, in that ease of use (EOU) is identified as a necessary pre-condition before perceived usefulness (PU) can be achieved. However, our research would suggest that this relationship is more interrelated and complex. For example, the initial web-surfing session was rated very highly by participants as providing them with a very useful skill—one which was intrinsically useful beyond the confines of their work responsibilities Thus, it was highly rated in terms of perceived usefulness. This served to increase their motivation to work with the technology, thereby addressing the ease of use construct, which was after all what we were emphasising in the first generic training phase where the threshold level of literacy was established by concentrating on ease of use issues, before the perceived usefulness was again addressed in the second training phase. Early signs suggest that the relationship between ease of use and perceived usefulness is not a simple linear sequential one whereby EOU must first be established as a necessary precondition for PU which in turn successfully leads to user acceptance of technology. Rather, the perceived usefulness of the technology can serve as a significant motivator initially which will help overcome EOU issues. Thus rather than operating in a sequential chain, the EOU and PU constructs may operate in a parallel cyclical fashion as indicated in Figure 3. This will be investigated further as the research progresses.

\section{References}

Adams, D, Nelson, R. and Todd, P. (1992) Perceived usefulness, perceived ease of use and user acceptance of information technology: a replication, MIS Quarterly, (16, 2), July, 1992, pp. 227-247. 
Innovative Training Model

Bocij, P, Chaffey, D, Greasley, A, Hickie, S, (1999) Business Information Systems: Technology, Development and Management, pp. 348-355, First Edition, Prentice Hall Publiciations.

Davis, F. (1989) Perceived usefulness, perceived ease of use and user acceptance of information technology, MIS Quarterly, $(13,3)$, September, 1989, pp. 319-340.

Davis, F., Bagozzi, R. and Warshaw, P. (1989) User acceptance of computer technology: comparison of two theoretical models, Management Science, (35, 6), August 1989, pp. 982-1003.

Fitzgerald, B. (1996) Formalised systems development methodologies: a critical perspective, Information Systems Journal, $(6,1)$, pp. 3-23.

Neumann, P.G (1995) Computer Related Risks, pp. 203-304, ACM Press / Addison Wesley.

Whitten, J.L, Bentley, D and Barlow, V.M, (1994), Systems Analysis and Design Methods, pp. 155-157, Third Edition, IRWIN Publishers, United States of America.
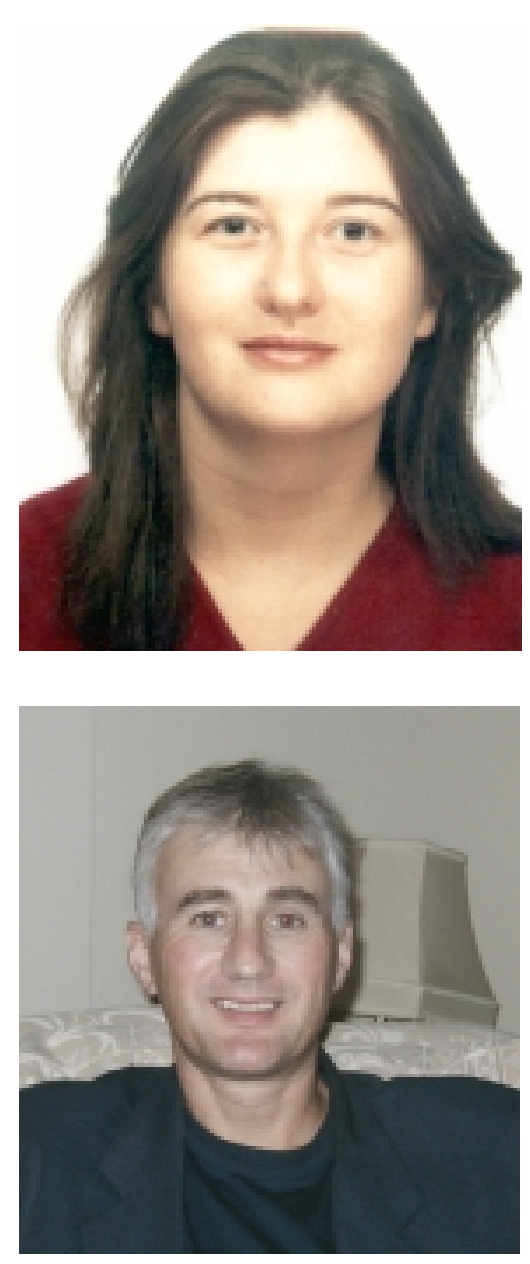

\section{Biographies}

Karen Neville holds both a Masters of Science in Management Information Systems and a Bachelor of Science in Business Information Systems from University College Cork, Ireland where she is employed as a College Lecturer. She is currently registered as a PhD student, under the supervision of Professor Philip Powell, at the University of Bath, UK. Her publications, to date, include papers focusing on ICT initiatives, ELearning and Educational Systems which have been published in some of the top information systems conferences, including the European Conference on Information Systems, Informing Science + IT Education, Americas Conference on Information Systems \& Business Information Technology Management Conference. However the focus of her research has now expanded to incorporate the areas of Knowledge Management and Security.

Brian Fitzgerald holds the Frederick A. Krehbiel II Chair in Innovation in Global Business and Technology at the University of Limerick, Ireland. He has a $\mathrm{PhD}$ from the University of London and has also held positions as Visiting Professor at Northern Illinois University in the US and the University of Gothenburg in Sweden. He is Associate Editor for The Information Systems Journal, and Data Base, two leading international journals in the IS field. His publications include four books and more than 50 papers, published in many of the premier international journals, including Communications of the ACM, IEEE Software, Information and Management, the Information Systems Journal, Information Systems and Operations Research, Information Technology \& People, the International Journal of Information Management, and the Journal of Information Technology. He has also presented his research at leading international conferences in Europe, Scandinavia, North America and Australia. Prior to taking up an academic position, he spent more than ten years in industry working on information systems development with companies in Ireland, Belgium and Germany. 